\title{
Reduced expression of regucalcin in young and aged mdx diaphragm indicates abnormal cytosolic calcium handling in dystrophin-deficient muscle
}

\author{
Philip Doran ${ }^{\text {a }}$, Paul Dowling ${ }^{\text {b }}$, Pamela Donoghue ${ }^{\text {a }}$, Maria Buffini ${ }^{\text {a }}$, Kay Ohlendieck ${ }^{\text {a,* }}$ \\ ${ }^{a}$ Department of Biology, National University of Ireland, Maynooth, Co. Kildare, Ireland \\ ${ }^{\mathrm{b}}$ School of Biotechnology, Dublin City University, Dublin, Ireland
}

Received 11 October 2005; received in revised form 9 December 2005; accepted 2 January 2006

Available online 31 January 2006

\begin{abstract}
The cytosolic $\mathrm{Ca}^{2+}$-binding protein regucalcin is involved in intracellular signaling and present in high abundance in the liver. Here, we could show by comparative mass spectrometry-based proteomics screening of normal versus dystrophic fibres that regucalcin of $33.9 \mathrm{kDa}$ and pI5.2 also exists in diaphragm muscle. Since the expression of sarcolemmal $\mathrm{Ca}^{2+}$-leak channels and luminal $\mathrm{Ca}^{2+}$-binding elements is altered in dystrophindeficient muscle, we initiated this study in order to determine whether additional soluble muscle proteins involved in $\mathrm{Ca}^{2+}$-handling are affected in muscular dystrophy. Following separation by two-dimensional gel electrophoresis, the spot pattern of the normal versus the mdx diaphragm muscle proteome was evaluated by densitometry. The expression levels of 20 major protein spots were shown to change and their identity determined by mass spectrometry. A 2-fold reduction of regucalcin in mdx diaphragm, as well as in dystrophic limb muscle and heart, was confirmed by immunoblotting in both young and aged mdx mice. The results from our proteomics analysis of dystrophic diaphragm support the concept that abnormal $\mathrm{Ca}^{2+}$-handling is involved in $\mathrm{x}$-linked muscular dystrophy. The reduction in key $\mathrm{Ca}^{2+}$-handling proteins may result in an insufficient maintenance of $\mathrm{Ca}^{2+}$-homeostasis and an abnormal regulation of $\mathrm{Ca}^{2+}$-dependent enzymes resulting in disturbed intracellular signaling mechanisms in dystrophinopathies.
\end{abstract}

(C) 2006 Elsevier B.V. All rights reserved.

Keywords: mdx diaphragm; Calcium homeostasis; Regucalcin; Muscle proteomics; Muscular dystrophy

\section{Introduction}

A primary deficiency in the Dp427 isoform of the membrane cytoskeletal protein dystrophin leads to a progressive muscle wasting process [1], making Duchenne muscular dystrophy the most frequent neuromuscular disorder in humans [2]. On the molecular level, deficiency in full-length dystrophin triggers the loss of a subset of surface proteins [3], including dystroglycans, sarcoglycans, sarcospan, syntrophins, dystrobrevins and associated signaling elements such as neuronal nitric oxide synthase [4-7]. In normal muscle fibres, the dystrophin-associated glycoprotein complex is thought to stabilize the fibre periphery by providing a linkage between the actin membrane cytoskeleton and the extracellular matrix component laminin [8]. When dystrophin is missing, this trans-sarcolemmal connection is

\footnotetext{
* Corresponding author. Tel.: +353 1708 3842; fax: +3531 7083845 .

E-mail address: kay.ohlendieck@nuim.ie (K. Ohlendieck).
}

impaired [9], resulting in an increased frequency of surface micro-rupturing [10]. During the natural membrane re-sealing process, $\mathrm{Ca}^{2+}$-leak channels are introduced into the dystrophic sarcolemma [11] causing elevated cytosolic $\mathrm{Ca}^{2+}$-levels that will eventually render muscle fibres more susceptible to necrosis [12]. It is not known how many pathophysiological steps are involved in this process, nor the nature of the hierarchy in the down-stream events leading to fibre degeneration [13,14], but it has been established that the physiological function of various ion-handling proteins [15-18] and excitation-contraction coupling elements $[19,20]$ is impaired in $\mathrm{x}$-linked muscular dystrophy.

Novel strategies for the large-scale analysis of differential gene expression and protein expression profiling of a particular cell type are represented by high-throughput transcriptomics and proteomics screening [21,22]. Both approaches have been applied to the study of muscular dystrophies using comparative transcriptomics [23-27] and 
mass spectrometry-based proteomics [17,28,29], and should give new insight into the molecular pathogenesis of these devastating disorders [30,31]. Proteomics is the qualitative and quantitative comparison of proteomes under varying biological conditions [32]. The muscle proteome can be defined as the protein complement expressed by a given muscle fibre genome [33]. Mass spectrometry-based proteomics has been successfully applied to the cataloguing of muscle proteins $[34,35]$, the identification of age-dependent protein nitration [36], the analysis of O-linked $\mathrm{N}$-acetylglucosamine proteins [37], the determination of fibre type-specific differences [38], the analysis of stimulation-induced changes in transforming muscle [39] and the expression profiling during muscle growth [40,41]. Recent studies employing proteomics technology to identify biomarkers in muscular dystrophy have focused on the soluble subproteome and the $\mathrm{Ca}^{2+}$-binding protein subproteome and could show that the expression of important proteins such as adenylate kinase and calsequestrin are greatly reduced in dystrophin-deficient fibres $[17,28]$. However, these investigations were performed with limb muscle specimens from the mdx mouse that exhibit a relatively mild dystrophic phenotype as compared to the seriously affected muscle fibres from Duchenne muscular dystrophy patients.

In contrast to $\mathrm{mdx}$ limb muscles, the murine $\mathrm{x}$-linked dystrophic diaphragm shows severe symptoms of skeletal muscle fibre degeneration that is more comparable to Duchenne muscular dystrophy [42]. This makes the $\mathrm{mdx}$ mouse diaphragm, which is missing dystrophin due to a point mutation [43], a highly suitable animal model for studying pathobiochemical and pathophysiological changes during fibre degeneration $[44,45]$. We therefore employed total diaphragm extracts to investigate the differential proteome expression pattern of normal versus dystrophic muscle fibres. Following twodimensional gel electrophoretic separation, the protein spot pattern was evaluated with $2 \mathrm{D}$ analysis software and protein species with a drastically changed expression level were identified via mass spectrometric fingerprinting. The proteomics approach demonstrated a drastic decrease of a protein named regucalcin [46] in the $\mathrm{mdx}$ diaphragm, which was confirmed by immunoblotting. Regucalcin has not previously been identified in diaphragm tissue and was originally described by Yamaguchi and Yamamoto [47] in rat liver cytosol and shown to regulate the activity of numerous $\mathrm{Ca}^{2+} /$ calmodulindependent enzymes [48]. Since regucalcin represents an important $\mathrm{Ca}^{2+}$-handling protein that is involved in various intracellular signaling mechanisms [49-51], its abnormal expression in dystrophin-deficient muscle agrees with the calcium hypothesis of muscular dystrophy that assumes that abnormal ion cycling plays a central role in skeletal muscle fibre degeneration [13].

\section{Materials and methods}

\subsection{Materials}

Electrophoresis grade chemicals, PhastGel Coomassie Blue R-350 tablets, silver staining kit, fluorescent Deep Purple stain, immobilized pH gradient (IPG) strips of pH 3-10 (linear) and IPG buffer of $\mathrm{pH} 3-10$ for isoelectric focusing, the
2D-Quant kit for determination of protein concentration in electrophoretic samples, the 2D-Clean-Up kit for removal of contaminants prior to isoelectric focusing, and acetonitrile were purchased from Amersham Biosciences/GE Healthcare (Little Chalfont, Buckinghamshire, UK). A matrix kit containing $\alpha$ cyano-4-hydroxycinnamic acid was obtained from Laserbiolabs, SophiaAntipolis, France. DNase-I enzyme was from Sigma Chemical Company, Dorset, UK and sequencing grade-modified trypsin was from Promega (Madison, WI, USA). For desalting of MS samples, C-18 Zip-Tips were purchased from Millipore Ireland B.V. (Carrigtwohill, Co. Cork, Ireland). Ultrapure Protogel acrylamide stock solutions were obtained from National Diagnostics (Atlanta, GA, USA). Primary antibodies were purchased from Cell Sciences, Canton, MA, USA (mAb HM3018 to regucalcin), Affinity Bioreagents, Golden, CO, USA (mAb VIIID $1_{2}$ to the fast $\mathrm{CSQ}_{\mathrm{f}}$ isoform of calsequestrin, mAb XIIC4 to sarcalumenin, and mAb 20A to the $\alpha_{2}$-subunit of the dihydropyridine receptor), Novacastra Laboratories Ltd., Newcastle upon Tyne, UK (mAb NCL-DYS1 against the Dp427 isoform of dystrophin, and mAb NCL-43 to $\beta$-dystroglycan), and Upstate Biotechnology Lake Placid, NY, USA (mAb C464.6 to the $\alpha_{1}$-subunit of the $\mathrm{Na}^{+} / \mathrm{K}^{+}$-ATPase, and mAb VIA4 $4_{1}$ to $\alpha$ dystroglycan). Peroxidase-conjugated secondary antibodies were obtained from Chemicon International, Temecula, CA USA. Immobilon NC nitrocellulose membranes, chemiluminescence substrates and protease inhibitors were purchased from Millipore, Bedford, MA, USA, Pierce and Warriner, Chester, UK, and Roche Diagnostics GmbH, Mannheim, Germany, respectively. All other chemicals used were of analytical grade and purchased from Sigma Chemical Company, Dorset, UK.

\subsection{Animal model of muscular dystrophy}

Primary deficiency in the Dp427 isoform of the membrane cytoskeletal protein dystrophin characterizes the mdx animal model of Duchenne muscular dystrophy, which is due to a point mutation in exon 23 [43]. As with most animal models, the mdx mouse does not represent a perfect replica of the human pathology. However, dystrophic mdx fibres, especially those of the diaphragm [42], show many of the secondary abnormalities observed in Duchenne muscular dystrophy. This includes elevated levels of serum creatine kinase, a dramatic reduction in the dystrophin-associated glycoprotein complex, abnormal excitation-contraction coupling and segmental fibre necrosis, as well as an increased susceptibility to osmotic shock and stretch-induced injury [45]. Thus, the mdx diaphragm is a suitable mouse model system for studying the most frequent $x$-linked neuromuscular disorder in humans. Male mice of the $\mathrm{Dmd}^{\mathrm{mdx}}$ strain (Jackson Laboratory, Bar Harbor, Maine) of varying age and agematched C57 controls were obtained through the Biomedical Facility of the National University of Ireland, Maynooth. For proteomics screening, the entire diaphragm muscle ( $\sim 100 \mathrm{mg}$ wet weight) was dissected from control C57 mice and $\mathrm{mdx}$ mice. The animal population used in this study consisted of 25 normal and 25 dystrophic mice and tissue samples were used for the initial optimization of experimental procedures and the subsequent detailed biochemical analyses. According to international standards of difference gel electrophoresis, seven control and seven dystrophic samples were used for the statistical analysis of the electrophoretically separated muscle proteome.

\subsection{Preparation of muscle protein extracts}

Equal amounts of normal and dystrophic diaphragm, limb muscle or heart tissue were quick-frozen in liquid nitrogen and ground up into a fine powder using a pestle and mortar. Subsequently, the muscle tissue powder was resuspended in $1 \mathrm{ml}$ of lysis buffer $(9.5 \mathrm{M}$ Urea, $4 \%$ (w/v) Chaps, $0.5 \%$ ampholytes $\mathrm{pH} 3-10,100 \mathrm{mM}$ DTT). To avoid protein degradation, the solution was supplemented with a freshly prepared protease inhibitor cocktail, consisting of $0.2 \mathrm{mM}$ pefabloc, $1.4 \mu \mathrm{M}$ pepstatin, $0.15 \mu \mathrm{M}$ aprotinin, $0.3 \mu \mathrm{M} \mathrm{E}-64,1 \mu \mathrm{M}$ leupetin, $0.5 \mathrm{mM}$ soybean trypsin inhibitor and $1 \mathrm{mM}$ EDTA [17]. In addition, to eliminate excessive viscosity of the total muscle extract due to the presence of DNA, $2 \mu 1$ of DNase-I (200 units) were added per $100 \mu 1$ of extraction buffer [39]. After incubation for $3 \mathrm{~h}$ at room temperature, with gentle vortexing every $10 \mathrm{~min}$ for $30 \mathrm{~s}$, the suspension was centrifuged at $4{ }^{\circ} \mathrm{C}$ for $20 \mathrm{~min}$ at $20,000 \times \mathrm{g}$ using a 5417R centrifuge from Eppendorf (Hamburg, Germany). The middle layer containing the extracted muscle proteins was carefully removed and a portion of it was saved for the determination of protein concentration using the 
2-D Quant kit from Amersham Biosciences/GE Healthcare (Little Chalfont, Buckinghamshire, UK). Protein extracts from normal and dystrophic diaphragm were immediately used for electrophoretic separation or stored at $-70^{\circ} \mathrm{C}$ in 200 $\mu \mathrm{g}$ protein aliquots until further processing.

\subsection{Two-dimensional gel electrophoresis}

In order to improve the quality of the two-dimensional separation of muscle proteins, interfering contaminants, such as lipids, salts and nucleic acids, were removed prior to isoelectric focusing, using the 2D-Clean-Up kit from Amersham Biosciences/GE Healthcare (Little Chalfont, Buckinghamshire, UK) as described by the manufacturer. Precipitated muscle proteins were resuspended in IEF rehydration buffer $(9.5 \mathrm{M}$ Urea, $4 \%$ (w/v) Chaps, $0.5 \%$ ampholytes $\mathrm{pH} 3-10$ and $100 \mathrm{mM}$ DTT) and resuspended by gentle vortexing and pipetting, and then subjected to ultra sonnication. Sample tubes were placed in a beaker of ice-cold water to avoid carbamylation of proteins, which may alter the $\mathrm{pI}$ of the protein thereby producing artefactual charge trains of proteins across the first-dimension gel. The ultra sonnicator (Bandelin Sonoplus Model HD-2200 with an MS-72 probe; Bandelin Electronic $\mathrm{GmbH}$, Berlin, Germany) was set at a low setting of $15 \%$, whereby sonnication was gradually increased. Samples were sonicated for $20 \mathrm{~s}$ with a 1-min cooling-off period, and this procedure was repeated 5 times. Samples were pelleted in a benchtop centrifuge for $30 \mathrm{~s}$ at $2000 \times g$ and then isoelectric focusing was performed using an IPGphor focusing system from Amersham Biosciences/GE Healthcare (Little Chalfont, Buckinghamshire, UK), with 13 $\mathrm{cm}$ IPG strips of $\mathrm{pH} 3-10$ (linear) and $50 \mu \mathrm{A}$ per strip. Total muscle protein extracts were diluted in the above described rehydration buffer (complemented with $0.05 \%(\mathrm{w} / \mathrm{v})$ bromophenol blue as a tracking dye) to achieve a final protein concentration of $200 \mu \mathrm{g}$ of protein per IPG strip. The following running conditions were used: $60 \mathrm{~min}$ at $100 \mathrm{~V}, 60 \mathrm{~min}$ at $500 \mathrm{~V}, 60 \mathrm{~min}$ at $1000 \mathrm{~V}, 60$ $\min$ at $2000 \mathrm{~V}, 60 \mathrm{~min}$ at $4000 \mathrm{~V}, 60 \mathrm{~min}$ at $6000 \mathrm{~V}$, and finally $150 \mathrm{~min}$ at $8000 \mathrm{~V}[17,39]$. Electrophoretic separation in the second dimension, as well as standard 1D gel electrophoresis, was performed with a $12 \%$ resolving SDSPAGE slab gel [52] using the Protean Xi-II cell from Bio-Rad Laboratories (Hemel Hemstead, Hert., UK). Prior to the 2D slab gel step, IPG strips were equilibrated for $10 \mathrm{~min}$ each in equilibration buffer $(30 \%(\mathrm{w} / \mathrm{v})$ glycerol, $20 \%$ $(\mathrm{w} / \mathrm{v})$ sucrose, $3 \%(\mathrm{w} / \mathrm{v})$ SDS, $50 \mathrm{mM}$ Tris- $\mathrm{HCl}, \mathrm{pH} 8.8)$ containing $100 \mathrm{mM}$ DTT and equilibration buffer supplemented with $0.25 \mathrm{M}$ ideoacetamide, respectively. Following brief washing in SDS running buffer, IEF strips were positioned on top of the second-dimension gel with the help of a $1 \%(\mathrm{w} / \mathrm{v})$ agarose sealing gel, poured on top of the strip and left to solidify. Slab gels were run at a constant voltage of $100 \mathrm{~V}$ for $1 \mathrm{~h}$, followed by $300 \mathrm{~V}$ for $3 \mathrm{~h}$ and a final electrophoretic step of $500 \mathrm{~V}$ for $2 \mathrm{~h}$.

\subsection{Protein visualization and image analysis}

After completion of the second dimension electrophoretic separation step, slab gels were stained with Hot Coomassie Brilliant Blue R-350. Alternatively, gels were stained with the fluorescent dye Deep Purple or Silver [17]. In contrast to silver staining, as applied in our previous study on the mdx hind limb muscle [17], in our experience Hot Coomassie staining has more compatibility with the MALDI-ToF MS peptide mass fingerprinting procedure for the identification of muscle protein species [39]. The hot Coomassie solution was made by dissolving one PhastGel Coomassie Blue tablet from Amersham Biosciences in 1.61 of $10 \%(\mathrm{v} / \mathrm{v})$ acetic acid to give a $0.025 \%(\mathrm{w} / \mathrm{v})$ staining solution. The solution was slowly heated to $90{ }^{\circ} \mathrm{C}$ in a fume hood and poured over the gel in a stainless steal tray. The tray was placed on top of a hot plate and the temperature was maintained for $5 \mathrm{~min}$ to aid staining of muscle proteins. The tray was then placed on a laboratory shaker for a further $10 \mathrm{~min}$ at room temperature. Destaining of the gel was achieved by placing it in a $10 \%$ (v/v) acetic acid solution and gentle rocking over night. Small piece of tissue paper was placed in the tray to soak up excess Coomassie dye and aid in the destaining process prior to densitometric analysis. Destained gels were processed immediately or were stored in a plastic folder with $10 \mathrm{ml}$ of a $1 \%$ (v/v) acetic acid solution and were kept at $4{ }^{\circ} \mathrm{C}$ until further use. For comparative proteomics, seven gels each from normal and $\mathrm{mdx}$ diaphragm were densitometrically evaluated using an Imagescanner II from Amersham Biosciences/GE Healthcare (Little Chalfont, Buckinghamshire, UK). The protein level of each 2D spot was expressed as a percentage of total spot volume in the whole gel. Image analysis was performed with Imagemaster 2-D Platinium Version 5.0 software (Amersham Biosciences/GE Healthcare, Little Chalfont, Buckinghamshire, UK).

\subsection{Sample preparation for mass spectrometry}

Prior to preparation for in-gel digestion, slab gels were washed twice for 10 min with deionized water and then Coomassie-stained spots of interest were excised using a blue $1 \mathrm{ml}$ pipette tip which top had been cut off to aid in the smooth transfer of gel plugs. Subsequently, excised gel plugs were placed in $1.5 \mathrm{ml}$ Eppendorf tubes that had been pre-siliconized with Sigmacote (Sigma Chemical Company, Dorset, UK), and were then destained, desalted and washed as follows: Gel plugs were first washed with $50 \%(\mathrm{v} / \mathrm{v})$ acetonitrile/ $0.1 \%(\mathrm{w} / \mathrm{v}) \mathrm{NH}_{4} \mathrm{HCO}_{3}$ for $15 \mathrm{~min}$. All remaining liquid above the gel plugs was removed and then sufficient amounts of acetonitrile were added to cover the gel plugs. Acetonitrile was removed following shrinkage of gel plugs and then rehydration was carried out for $5 \mathrm{~min}$ in a minimum volume of $50 \mathrm{mM}$ $\mathrm{NH}_{4} \mathrm{HCO}_{3}$. An equal volume of acetonitrile was added and after $15 \mathrm{~min}$ of incubation all the liquid was removed and the protein-containing gel plugs were shrunk in acetonitrile. Following removal of acetonitrile, the gel plugs were dried down for 30 min using a Heto type vacuum centrifuge from Jouan Nordic A/S (Allerod, Denmark). Rehydration of individual gel pieces was then accomplished by adding sufficient amounts of digestion buffer ( $1 \mu \mathrm{g}$ of trypsin

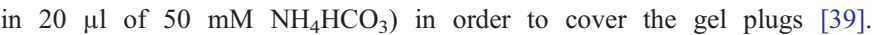
Sequencing-grade trypsin was obtained from Promega (Madison, WI, USA). More digestion buffer was added if all the initial volume had been absorbed by the gel pieces. The samples were then incubated at $37{ }^{\circ} \mathrm{C}$ for $60 \mathrm{~min}$. Excess enzyme solution was removed and approximately $3 \mu \mathrm{l}$ of $50 \mathrm{mM} \mathrm{NH}_{4} \mathrm{HCO}_{3}$ was added to each gel plug in order to keep gel pieces wet overnight. Following exhaustive digestion overnight at $37^{\circ} \mathrm{C}$, samples were centrifuged at $12,000 \times \mathrm{g}$ for $10 \mathrm{~min}$ using a model $5417 \mathrm{R}$ bench top centrifuged from Eppendorf (Hamburg, Germany). The supernatant was carefully removed from each tube and placed into a clean and siliconized plastic tubes. The resulting peptides were extracted by three sequential extraction steps each of $30 \mathrm{~min}$ duration and a volume of $40 \mu \mathrm{l}$ each. The solvent of the first extraction consisted of $50 \%(\mathrm{v} / \mathrm{v})$ acetonitrile/0.1\% (v/v) trifluoroacetic acid. Extraction was aided by sonication in a Branson-3510 water bath (Branson Ultrasonic Corporation, Danbury, CT, USA) for $30 \mathrm{~min}$. Samples were the spun down for $30 \mathrm{~s}$ at $2000 \times \mathrm{g}$. The solvents for the two remaining extraction steps were $60 \%$ $(\mathrm{v} / \mathrm{v})$ acetonitrile/0.1\% (v/v) trifluoroacetic acid and $80 \%(\mathrm{v} / \mathrm{v})$ acetonitrile/ $0.1 \%(\mathrm{v} / \mathrm{v})$ trifluoroacetic acid. The solutions from the three separate extraction procedures were combined and concentrated in a vacuum centrifuge as described above. Peptide preparations resulting from the processing of individual gel plugs were resuspended in $8 \mu \mathrm{l}$ of $3 \%(\mathrm{v} / \mathrm{v})$ trifluoroacetic acid and stored at $-70{ }^{\circ} \mathrm{C}$ until analysed by mass spectrometry.

\subsection{MALDI-ToF mass spectrometric analysis}

Matrix-assisted laser desorption ionization time-of-flight (MALDI-ToF) tryptic peptide mass fingerprinting of in-gel digests from normal versus dystrophic muscle protein species was conducted as previously described [17,39]. Tryptic peptides from individual samples were desalted using C-18 Zip-Tips (Millipore, Carrigtwohill, Co. Cork, Ireland) and eluted onto the sample plate with the matrix solution $(5 \mathrm{mg} / \mathrm{ml} \alpha$-cyano-4 hydroxycinnamic acid in $50 \%(\mathrm{v} / \mathrm{v})$ acetonitrile $/ 0.1 \%(\mathrm{v} / \mathrm{v})$ trifluoroacetic). Mass spectra were recorded using an Ettan MALDI-ToF Pro instrument from Amersham Biosciences (Little Chalfont, Buckinghamshire, UK) operating in the positive reflector mode at the following parameters: accelerating voltage $20 \mathrm{kV}$; and pulsed extraction: on (focus mass 2500). Standard peaks of angiotensin III $(897.5 \mathrm{~m} / \mathrm{z})$ and ACTH $(2465.19 \mathrm{~m} / \mathrm{z})$ and trypsin autolysis peaks at $\mathrm{m} / \mathrm{z} 842.50$ and $m / z 2211.104$ were used for internal calibration [39]. MALDI evaluation software (Amersham Biosciences/GE Healthcare, Little Chalfont, Buckinghamshire, UK) was used for the analysis of mass spectra and protein identification was achieved with the PMF ProFound search engine for peptide mass fingerprints. All certainty hits of diaphragm muscle proteins generated by the ProFound search engine were matched against the publicly available search engine Mascot (http://www.matrixscience.com). 


\subsection{Immunoblot analysis}

Electrophoretic transfer of proteins to Immobilin NC-pure nitrocellulose membranes was carried out according to Towbin et al. [53] using a Bio-Rad Transblot cell (Bio-Rad Labs., Hemel Hempstead, Herts., U.K.). Proteins were transferred at $4{ }^{\circ} \mathrm{C}$ for $80 \mathrm{~min}$ at $100 \mathrm{~V}$. Efficiency of transfer was evaluated by Ponceau-S-Red staining of nitrocellulose membranes, followed by destaining in phosphate buffered saline (PBS; $50 \mathrm{mM}$ sodium phosphate, $0.9 \%(\mathrm{w} / \mathrm{v}) \mathrm{NaCl}$, $\mathrm{pH}$ 7.4). Membranes were blocked for $1 \mathrm{~h}$ in $5 \%(\mathrm{w} / \mathrm{v})$ fat-free milk powder in PBS. Membranes were then incubated for $3 \mathrm{~h}$ at room temperature with primary antibody, appropriately diluted with blocking buffer. Nitrocellulose replicas were subsequently twice washed for $10 \mathrm{~min}$ in blocking solution and then incubated with an appropriate dilution of the corresponding peroxidaseconjugated secondary antibodies for $1 \mathrm{~h}$ at room temperature. Nitrocellulose membranes were washed twice for $10 \mathrm{~min}$ in blocking solution and twice rinsed for $10 \mathrm{~min}$ in PBS. Visualization of immuno-decorated 1D bands or 2D spots was carried out with the SuperSignal enhanced chemiluminescence kit from Pierce and Warriner (Chester, Cheshire, U.K.) [54]. Densitometric scanning of immunoblots was performed on a Molecular Dynamics 300S computing densitometer (Sunnyvale, CA, USA) with Imagequant V3.0 software.

\section{Results}

Dystrophin-deficient muscle fibres exhibit abnormal excitation-contraction coupling and impaired $\mathrm{Ca}^{2+}$-handling. Here, we have used mass spectrometry-based proteomics and twodimensional immunoblotting in order to determine whether the expression of novel $\mathrm{Ca}^{2+}$-binding elements is affected in $\mathrm{x}$ linked muscular dystrophy. Since the diaphragm from the $\mathrm{mdx}$ mouse model of Duchenne muscular dystrophy is a severely affected type of muscle, total diaphragm extracts rather than hind limb muscle preparations were used to evaluate the differential proteome expression pattern of normal versus dystrophic muscle fibres.

\subsection{Reduced expression of luminal $\mathrm{Ca}^{2+}$-binding proteins in dystrophic diaphragm}

In analogy to the established finding that the luminal $\mathrm{Ca}^{2+}$ binding proteins calsequestrin and sarcalumenin are reduced in dystrophic mdx hind limb muscle preparations [16,17], we can show here that the expression of both sarcoplasmic reticulum components is also affected in the mdx diaphragm. Our initial 1D immunoblotting survey illustrated that deficiency in the dystrophin isoform Dp427 (Fig. 1A) is associated with a drastic reduction in $\alpha / \beta$-dystroglycan (Fig. $1 \mathrm{C}, \mathrm{D}$ ), the $\mathrm{Ca}^{2+}$-binding protein calsequestrin of the terminal cisternae region (Fig. 1E) and the $\mathrm{Ca}^{2+}$-shuttle element sarcalumenin of the longitudinal tubules (Fig. 1F). Thus, the two most abundant luminal $\mathrm{Ca}^{2+}$ reservoir proteins that occupy a central position in the regulatory apparatus of the excitation-contraction-relaxation cycle of skeletal muscle are severely reduced in the dystrophic diaphragm. In two-dimensional gels of total diaphragm extracts, as shown below in Fig. 2, distinct spots did not correlate with the isoelectric point and molecular mass of these two essential $\mathrm{Ca}^{2+}$-binding proteins of apparent $63 \mathrm{kDa}$ and $160 \mathrm{kDa}$. The relative density of luminal components of the sarcoplasmic reticulum appears to be too low for proper representation by protein dye-staining, following extraction, isoelectric focusing and slab gel electrophoresis of total muscle preparations. In

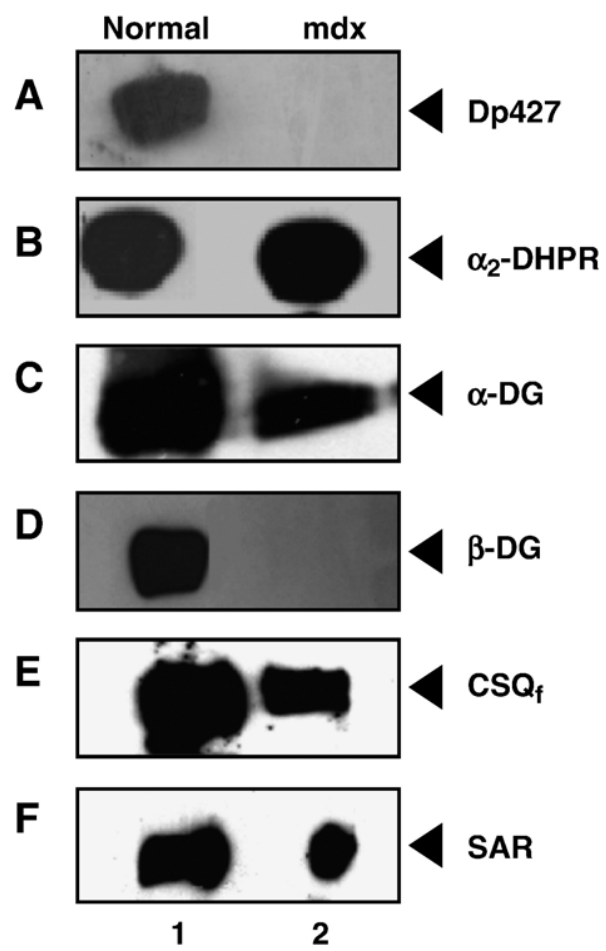

Fig. 1. One-dimensional immunoblot analysis of luminal $\mathrm{Ca}^{2+}$-binding proteins in mdx diaphragm. Shown are identical 1D immunoblots labelled with antibodies to the Dp427 isoform of dystrophin (A), the $\alpha_{2}$-subunit of the dihydropyridine receptor (DHPR; B), $\alpha$-dystroglycan ( $\alpha$-DG; C), $\beta$-dystroglycan $(\beta-D G ; D)$, the fast $\mathrm{CSQ}_{\mathrm{f}}$ isoform of calsequestrin $(\mathrm{E})$, and sarcalumenin (SAR; F). Lanes 1 and 2 represent total protein extracts from normal and dystrophic mdx diaphragm muscle fibres, respectively.

contrast to the reduced density of calsequestrin and sarcalumenin in mdx diaphragm, the auxiliary $\alpha_{2}$-subunit of the voltagesensing dihydropyridine receptor from the transverse tubules was shown to exhibit very comparable expression levels in normal versus dystrophic diaphragm (Fig. 1B). This agrees with previous findings from $\mathrm{mdx}$ hind limb preparations and demonstrates equal loading of normal versus dystrophic diaphragm fractions in individual gel lanes.

\subsection{Comparative two-dimensional gel electrophoresis of normal versus mdx diaphragm}

Mouse skeletal muscle is a highly complex and specialized mammalian tissue that contains a considerable amount of insoluble protein species and approximately half of its protein components constitute the contractile apparatus. These biological facts make it more difficult to separate crude muscle extracts in two-dimensional gels, as compared, for example, to bacterial preparations, and therefore necessitated initial optimization experiments. Following electrophoretic trials with varying amounts of protein (not shown), the optimum amount of diaphragm muscle protein per isoelectric focusing strip was found to be approximately $200 \mu \mathrm{g}$ in order to perform a comparative proteomics approach. A lower protein concentration led to minimal cross-contamination between individual protein species, but resulted in a weak staining pattern. A higher 


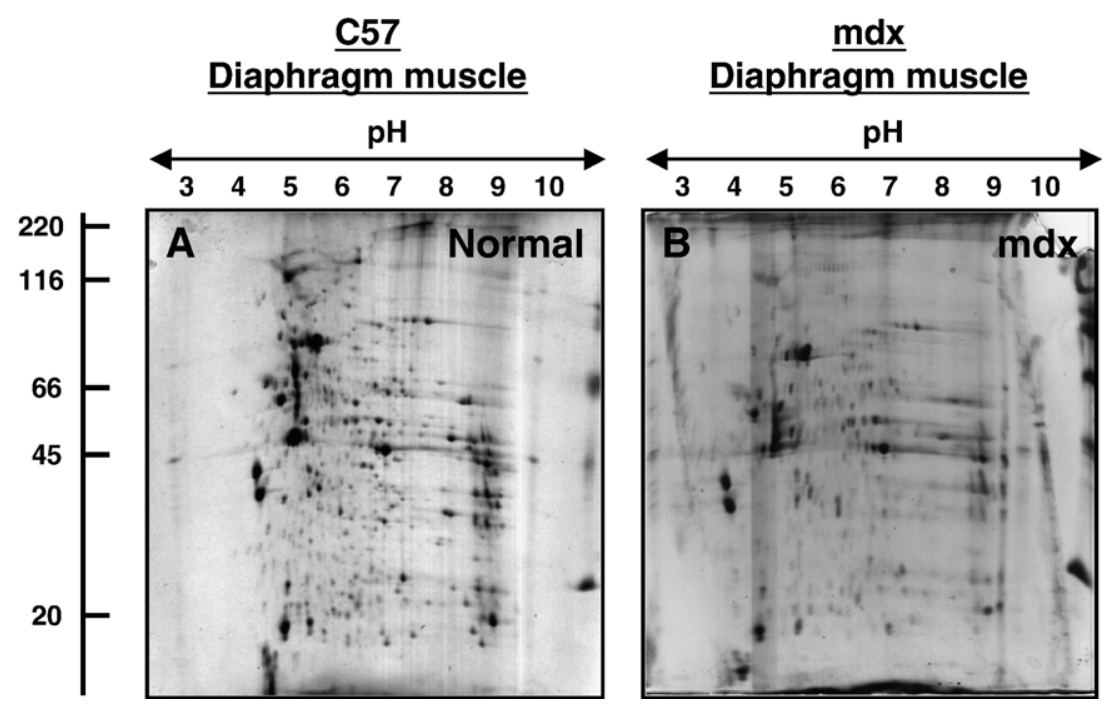

Fig. 2. Two-dimensional gel electrophoretic comparison between normal and mdx diaphragm muscle extracts. Shown are Hot Coomassie-stained 2D gels of total protein extracts from normal (A) and dystrophic $\mathrm{mdx}$ (B) diaphragm muscle. The $\mathrm{pH}$-values of the first dimension gel system and molecular mass standards (in $\mathrm{kDa}$ ) of the second dimension are indicated on the top and on the left of the panels, respectively.

protein concentration led to considerable protein streaking, probably due to artefactual charge trains of proteins in the first dimension and spot smearing caused by abnormal electrophoretic mobility of abundant protein species in the second dimension. Thus, although it is possible to load a considerably higher concentration of protein per first dimension gel, in our experience cross-contamination of the two-dimensional spot pattern with abundant muscle proteins such as myosin, actin, troponin and tropomyosin prevents an approach with more than $200 \mu \mathrm{g}$ protein when using mouse diaphragm muscle preparations.

Fig. 2 shows representative two-dimensional gels of the normal C57 mouse diaphragm proteome versus the dystrophic mdx diaphragm proteome. Gel labelling using silver (not shown) or the fluorescent Amersham dye Deep Purple (see below) revealed similar protein patterns. However, in our experience Hot Coomassie staining is the most compatible protein staining method for a subsequent mass spectrometric analysis and is therefore shown here. Well-established muscle marker proteins ranging from $16.1 \mathrm{kDa}$ (superoxide dismutase) to $223.7 \mathrm{kDa}$ (myosin $\beta$-heavy chain) in relative molecular mass and with a pI-range of approximately $\mathrm{pH} 4.1$ (troponin $\mathrm{C}$ ) to $\mathrm{pH} 9.2$ (isocitrate dehydrogenase) could be separated. See below for the identification of these proteins by MALDI-ToF MS tryptic peptide mass fingerprinting from in-gel digests. The overall two-dimensional spot pattern of the gels shown in Fig. $2 \mathrm{~A}, \mathrm{~B}$ is comparable to published studies on the electrophoretic separation of total skeletal muscle extracts [34,35] and agrees with international data banks, such as the SWISS-2DPAGE database (http://www.us.expasy.org/ch2d/). Abundant skeletal muscle markers form characteristic landmark spots [33-35] are clearly present in our slab gel, such as serum albumin (70.7 $\mathrm{kDa} / \mathrm{pI} 5.8), \alpha$-actin $(42.4 \mathrm{kDa} / \mathrm{pI} 5.2)$, creatine kinase (43.3 $\mathrm{kDa} / \mathrm{pI} 6.6)$, the two tropomyosin isoforms TPM- $1 \alpha(32.8 \mathrm{kDa} /$ pI 4.7) and TPM-2 $\beta$ (32.9 kDa/pI 4.7), and the myosin light chain $(20.7 \mathrm{kDa} / \mathrm{pI} 5.0)$. The main protein spot pattern of the mdx diaphragm preparation was shown to be relatively comparable to that from normal control fibre specimens (Fig. $2 \mathrm{~A}, \mathrm{~B})$. Thus, to properly determine potential changes in the expression levels of individual muscle protein species, we carried out a densitometric analysis of the two-dimensional spot pattern and identified proteins via mass spectrometry.

\subsection{Two-dimensional immunoblot analysis of luminal $\mathrm{Ca}^{2+}$-binding proteins in dystrophic diaphragm}

To demonstrate that the two-dimensional gel electrophoretic separation process is suitable for the analysis of $\mathrm{Ca}^{2+}$-binding proteins from diaphragm muscle, and in order to confirm the dystrophic status of the $\mathrm{mdx}$ preparations, nitrocellulose replicas of the gels shown in Fig. 2 were immuno-decorated with established monoclonal antibodies. In analogy to the onedimensional immunoblotting presented in Fig. 1, the antibody staining patterns in Fig. 3 clearly illustrate a reduction in dystrophin-associated glycoproteins and $\mathrm{Ca}^{2+}$-regulatory elements in dystrophic mdx muscle. In contrast to the relatively comparable levels of the surface marker enzyme $\mathrm{Na}^{+} / \mathrm{K}^{+}$ATPase in normal versus dystrophic specimens (Fig. 3A, F), the sarcolemmal protein $\beta$-dystroglycan (Fig. 3C, H) and its extracellular binding partner $\alpha$-dystroglycan (Fig. 3B, G) are greatly reduced in $\mathrm{mdx}$ diaphragm. Since the $\alpha / \beta$-dystroglycan dimer forms the backbone of the dystrophin-glycoprotein complex by forming an indirect linkage between the extracellular matrix protein laminin and the dystrophin-associated actin cytoskeleton in healthy muscle fibres, this result clearly established the dystrophic phenotype of the mdx diaphragm specimens used in this study. It also demonstrated that twodimensional gel electrophoresis is suitable for the comparative analysis of the protein complement from normal versus dystrophic diaphragm muscle. The immuno-decoration of two key $\mathrm{Ca}^{2+}$-binding proteins of the sarcoplasmic reticulum, the fast $\mathrm{CSQ}_{\mathrm{f}}$ isoform of calsequestrin and sarcalumenin, showed a 


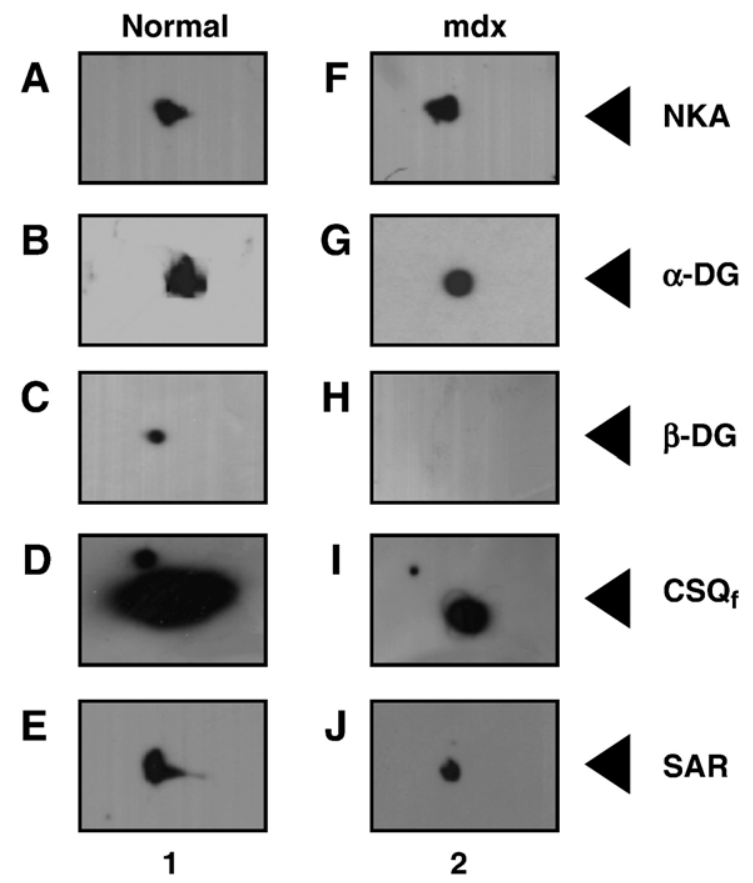

Fig. 3. Two-dimensional immunoblot analysis of luminal $\mathrm{Ca}^{2+}$-binding proteins in $\mathrm{mdx}$ diaphragm. Shown are $2 \mathrm{D}$ immunoblots focusing on the area of antibody-decorated protein spots. Blots correspond to the Hot Coomassiestained gels in Fig. 2 and were labelled with antibodies to the $\mathrm{Na}^{+} / \mathrm{K}^{+}$-ATPase (NKA; A, F), $\alpha$-dystroglycan ( $\alpha$-DG; B, G), $\beta$-dystroglycan ( $\beta$-DG; C, H), the fast $\mathrm{CSQ}_{\mathrm{f}}$ isoform of calsequestrin (D, I), and sarcalumenin (SAR; E, J). Lanes 1 and 2 represent total protein extracts from normal (A-E) and dystrophic $\mathrm{mdx}$ $(\mathrm{F}-\mathrm{J})$ diaphragm muscle fibres, respectively.

drastic reduction in both luminal elements (Fig. 3D-J). Thus, both the major $\mathrm{Ca}^{2+}$-reservoir protein of the terminal cisternae and the $\mathrm{Ca}^{2+}$-shuttle protein of the longitudinal tubules exhibit an abnormal density in $\mathrm{mdx}$ diaphragm.

\subsection{Mass spectrometric fingerprinting of the diaphragm muscle proteome}

As outlined above, two-dimensional gel electrophoresis of crude tissue preparations under-represents certain protein species, such as integral membrane proteins, very highmolecular-mass proteins, low-abundance proteins, and very acidic proteins. We were therefore not able to determine the presence of large proteins or tightly membrane-associated proteins that play an important role in the molecular pathogenesis of $x$-linked muscular dystrophy, e.g., the fulllength muscle dystrophin isoform of apparent $427 \mathrm{kDa}$ and the $565 \mathrm{kDa} \mathrm{Ca}^{2+}$-release channel monomer of the skeletal muscle ryanodine receptor isoform RyR1. The majority of the proteins seen in the Hot Coomassie-stained gel in Fig. 4 probably represent mostly soluble protein components of diaphragm fibres or at least protein species that do not exist in detergentinsoluble membrane complexes. Image analysis with Amersham Biosciences Imagemaster 2-D Platinium software recognized on this reference gel 333 individual protein spots. Overall, 50 proteins were identified by mass spectrometry (Table 1) including 20 major protein spots that exhibited a differential expression pattern between normal and dystrophic diaphragm. The expression of 11 of these muscle proteins was decreased in the mdx mouse model and 9 of them showed an increased abundance as compared to control mice (Table 2). An additional 30 skeletal muscle marker proteins were identified by mass spectrometric fingerprinting in order to establish the presence of landmark protein spots. The unique positioning of these muscle proteins with their known molecular mass and isoelectric point demonstrated that our gel electrophoretic separation pattern is comparable to international 2D-PAGE banks, and that our experimental protocols sufficiently and reproducibly separated major protein species of mouse diaphragm muscle.

The results presented in Fig. 4 and Table 1 clearly showed the presence of key muscle proteins in the two-dimensional reference gel from normal diaphragm. As outlined above, landmark spots $5,19,23,30,33$ and 45 represent the highly abundant muscle proteins serum albumin, $\alpha$-actin, creatine kinase, tropomyosin isoform TPM- $1 \alpha$, tropomyosin isoform TPM- $2 \beta$ and the myosin light chain, respectively. Besides these contractile proteins and important metabolic factors, less abundant protein spots corresponded to cellular components involved in cytoskeleton formation, mitochondrial function, metabolic control, glycolysis, ion homeostasis, muscle contraction, and chaperone function. Interestingly, slow-twitch cardiac isoforms of the myosin $\beta$-chain (spot 1) and $\alpha$-actin (spot 27) were found to be present in mouse diaphragm muscle, confirming the special status of diaphragm fibres within the skeletal muscle group of mammalian tissues. The identified skeletal muscle markers could be grouped as proteins involved in contraction (myosin heavy chain/spot 1; actin/spots 19 and 27; tropomyosin/spots 30 and 33; myosin light chain/spots 40 , 45 and 47; troponin/spots 41 and 49), mitochondrial enzymes

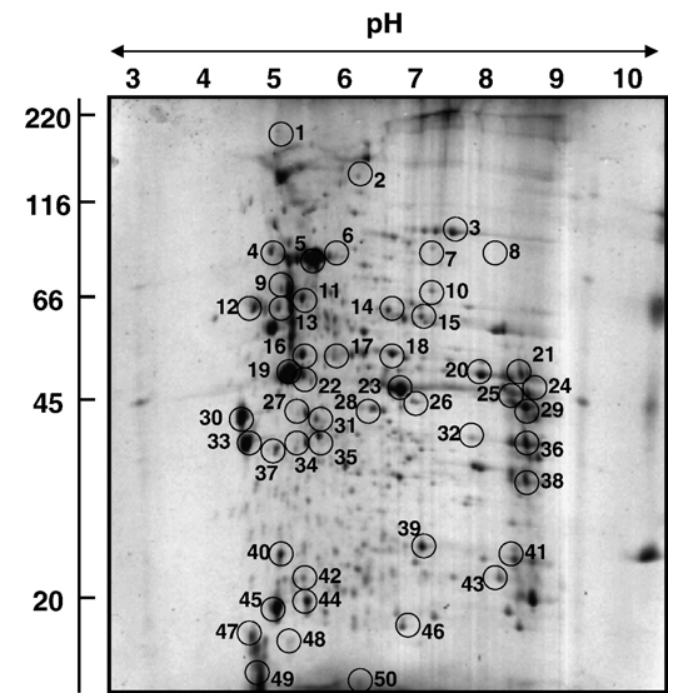

Fig. 4. Two-dimensional gel electrophoretic reference gel of diaphragm muscle. Shown is a representative Hot Coomassie-stained 2D gel of total protein extracts from normal mouse diaphragm muscle. The $\mathrm{pH}$-values of the first dimension gel system and molecular mass standards (in $\mathrm{kDa}$ ) of the second dimension are indicated on the top and on the left of the panels, respectively. Proteins that have been identified by MALDI-ToF MS tryptic peptide mass fingerprinting from ingel digests are marked by circles and are numbered 1 to 50. See Table 1 for a detailed listing of identified muscle protein species. 
Table 1

List of identified proteins in 9-week-old mouse diaphragm muscle using mass spectrometry-based proteomics

\begin{tabular}{|c|c|c|c|c|c|}
\hline Spot no. & Name of identified protein & Sequence coverage $(\%)$ & Molecular mass (kDa) & Isoelectric point $(\mathrm{pI})$ & Protein accession no. \\
\hline 1 & Cardiac myosin $\beta$-heavy chain & 10.5 & 223.66 & 5.6 & gi[16508127] \\
\hline 2 & Carbamoyl-phosphate synthase & 9.3 & 166.99 & 6.4 & $\operatorname{gi}[51705066]$ \\
\hline 3 & Aconitase 2, mitochondrial & 8.6 & 86.22 & 8.4 & gi[13435538] \\
\hline 4 & Heat shock $70 \mathrm{kDa}$ protein 5 & 21.4 & 72.52 & 5.0 & $\operatorname{gi}[31981722]$ \\
\hline 5 & Serum albumin precursor & 26.0 & 70.73 & 5.8 & gi[5915682] \\
\hline 6 & Serum albumin & 23.5 & 70.73 & 5.8 & $\operatorname{gi}[3647327]$ \\
\hline 7 & Galactosidase, $\beta 1$ & 15.9 & 73.46 & 6.9 & gi[1730192] \\
\hline 8 & RecQ helicase-like protein & 15.1 & 73.50 & 9.0 & gi[46092353] \\
\hline 9 & Vimentin & 27.5 & 53.76 & 5.1 & $\operatorname{gi}[55408]$ \\
\hline 10 & Dihydrolipoamide dehydrogenase & 20.4 & 54.76 & 8.3 & gi[6014973] \\
\hline 11 & Desmin & 24.9 & 53.54 & 5.2 & $\operatorname{gi}[33563250]$ \\
\hline 12 & Atp $5 \mathrm{~b}$ protein & 27.0 & 56.28 & 5.2 & gi[23272966] \\
\hline 13 & Vimentin & 20.2 & 51.60 & 4.9 & $\operatorname{gi}[2078001]$ \\
\hline 14 & Fbxo11 protein & 10.4 & 58.58 & 6.6 & gi[33243977] \\
\hline 15 & Aldh2 protein & 18.1 & 57.03 & 7.7 & gi[13529509] \\
\hline 16 & $\begin{array}{l}\text { Ubiquinol-cytochrome } c \text { reductase } \\
\text { core protein } 1\end{array}$ & 14.4 & 53.46 & 5.8 & $\operatorname{gi}[46593021]$ \\
\hline 17 & Enolase $3, \beta$-subunit & 32.0 & 47.35 & 6.7 & gi[6679651] \\
\hline 18 & Serum albumin, fragment & 24.5 & 53.00 & 5.5 & gi[11277085] \\
\hline 19 & $\operatorname{Actin}(\alpha 1)$ & 22.5 & 42.38 & 5.2 & gi[49864] \\
\hline 20 & Creatine kinase, mitochondrial & 31.3 & 47.91 & 9.1 & gi[38259206] \\
\hline 21 & Isocitrate dehydrogenase 2 & 10.0 & 51.34 & 9.2 & gi[37748684] \\
\hline 22 & Unnamed protein product & 21.8 & 42.92 & 5.6 & gi[26342825] \\
\hline 23 & Creatine kinase, $\mathrm{M}$ chain & 18.9 & 43.26 & 6.6 & gi[6671762] \\
\hline 24 & Unnamed protein product & 16.1 & 42.03 & 9.6 & gi[26338608] \\
\hline 25 & Aldolase 1, isoform A & 27.5 & 39.75 & 8.9 & gi[44890261] \\
\hline 26 & Aspartate aminotransferase & 10.7 & 46.50 & 6.7 & $\operatorname{gi}[871422]$ \\
\hline 27 & Cardiac $\alpha$-actin, fragment & 18.1 & 42.05 & 5.2 & gi[627834] \\
\hline 28 & $2^{\prime}-5^{\prime}$ oligoadenylate synthetase & 14.1 & 43.51 & 5.5 & gi[21326001] \\
\hline 29 & Unnamed protein product & 9.9 & 37.37 & 8.9 & gi[12855049] \\
\hline 30 & Tropomyosin (TPM-2 $\beta)$ & 21.5 & 32.93 & 4.7 & gi[11875203] \\
\hline 31 & Pyruvate dehydrogenase & 22.0 & 39.26 & 6.4 & gi[18152793] \\
\hline 32 & $\begin{array}{l}\text { Electron transferring flavoprotein, } \\
\alpha \text {-polypeptide }\end{array}$ & 34.2 & 35.27 & 8.8 & $\operatorname{gi}[31981826]$ \\
\hline 33 & Tropomyosin (TPM-1 $\alpha)$ & 33.1 & 32.75 & 4.7 & gi[20522240] \\
\hline 34 & Malate dehydrogenase & 24.9 & 33.63 & 6.2 & gi[319837] \\
\hline 35 & Aldehyde reductase & 18.2 & 36.80 & 6.9 & gi[29374169] \\
\hline 36 & $\begin{array}{l}\text { Glyceraldehyde-3-phosphate } \\
\text { dehydrogenase-like protein }\end{array}$ & 33.6 & 36.09 & 8.4 & $\operatorname{gi}[51710824]$ \\
\hline 37 & Regucalcin & 37.8 & 33.90 & 5.2 & gi[6677739] \\
\hline 38 & Voltage-dependent anion channel & 36.0 & 30.85 & 8.8 & gi[13786200] \\
\hline 39 & Carbonic anhydrase 3 & 28.1 & 29.63 & 6.9 & gi[31982861] \\
\hline 40 & Myosin light chain 3 & 54.9 & 22.52 & 5.0 & gi[33563264] \\
\hline 41 & Troponin I, fast muscle TnI-2 & 37.4 & 21.51 & 8.8 & gi[6678391] \\
\hline 42 & Adenylate kinase 1 & 31.9 & 23.33 & 5.7 & gi[10946936] \\
\hline 43 & Glutathione S-transferase & 15.1 & 25.91 & 7.8 & gi[33468899] \\
\hline 44 & Trioesphosphate isomerase & 19.5 & 22.72 & 5.6 & $\operatorname{gi}[1864018]$ \\
\hline 45 & Myosin light chain A1 & 55.9 & 20.69 & 5.0 & gi[91114] \\
\hline 46 & Cryab protein $/ \alpha B$-crystallin & 28.0 & 20.05 & 6.8 & gi[14789702] \\
\hline 47 & Myosin light chain $2 \mathrm{v}$ & 38.0 & 18.77 & 4.9 & gi[38511915] \\
\hline 48 & ATP synthase, mitochondrial & 39.8 & 18.79 & 5.5 & $\operatorname{gi}[51980458]$ \\
\hline 49 & Troponin $\mathrm{C}$, fast muscle $\mathrm{TnC}$ & 28.1 & 18.15 & 4.1 & gi[19354422] \\
\hline 50 & Superoxide dismutase 1 & 31.8 & 16.10 & 6.0 & gi[45597447] \\
\hline
\end{tabular}

associated with the formation of acetyl-coenzyme A (dihydrolipoamide dehydrogenase/spot 10; pyruvate dehydrogenase/ spot 31), the citric acid cycle (aconitase/spot 3; isocitrate dehydrogenase/spot 21 ; malate dehydrogenase/spot 34), oxalacetate convertion (aspartate aminotransferase/spot 26), electron transport (ubiquinol-cytochrome $c$ reductase/spot 16), ATP synthesis (mitochondrial ATP synthase/spot 48), fatty acid oxidation (electron transferring flavoprotein/spot 32), and biosynthesis of pyrimidines (carbamoyl-phosphate synthase/ spot 2), as well as control function of translation $\left(2^{\prime}-5^{\prime}\right.$ oligoadenylate synthetase/spot 28), unwinding of doublehelical nucleic acid (RecQ helicase/spot 8), intermediate filament formation (vimentin/spots 9 and 13; desmin/spot 11), chaperone function (heat shock protein HSP70/spot 4; cryab protein/spot 46), fatty acid transportation and protein reservoir function (albumin/spots 5, 6 and 18), aldehyde metabolism 
Table 2

List of identified proteins in 9 week-old $\mathrm{mdx}$ mouse diaphragm muscle that exhibit a change in expression as judged by comparative proteomics

\begin{tabular}{lll}
\hline Spot no. & Name of identified protein & Fold-change $+/-$ \\
\hline 7 & Galactosidase, $\beta 1$ & -2.7 \\
9 & Vimentin & +2.2 \\
10 & Dihydrolipoamide dehydrogenase & -2.3 \\
11 & Desmin & +2.1 \\
13 & Vimentin & +2.6 \\
14 & Fbxo11 protein & -2.7 \\
15 & Aldh2 protein & -2.2 \\
18 & Serum albumin, fragment & +2.8 \\
21 & Isocitrate dehydrogenase 2 & -2.0 \\
22 & Unnamed protein product & +2.9 \\
23 & Creatine kinase, M chain & +3.0 \\
25 & Aldolase 1, A isoform & +2.0 \\
32 & Electron transferring flavoprotein, $\alpha$-polypeptide & +5.7 \\
34 & Malate dehydrogenase & +3.8 \\
36 & Glyceraldehyde-3-phosphate & -5.2 \\
& dehydrogenase- like protein & \\
37 & Regucalcin & -2.0 \\
38 & Voltage-dependent anion channel 1 & -3.3 \\
42 & Adenylate kinase 1 & -6.0 \\
47 & Cryab protein/ $\alpha$ B-crystallin & -4.0 \\
48 & Myosin light chain 2v & -2.4 \\
\hline & & \\
\hline
\end{tabular}

(aldehyde reductase/ spot 35, aldehyde dehydrogenase/spot 15), glycolysis (aldolase/spot 25; enolase/spot 17; glyceraldehyde-3phosphate dehydrogenase/spot 36; triosephosphate isomerase/ spot 44), nucleotide metabolism (Atp5b protein/spot 12; mitochondrial creatine kinase/spot 20; creatine kinase Mchain/spot 23; adenylate kinase/spot 42), protein ubiquination (Fbxo11 protein/spot 14), carbohydrate metabolism (galactosidase/spot 7), regulation of acid-base balance (carbonic anhydrase/spot 39), superoxide radical inactivation (superoxide dismutase/spot 50), leucotrine metabolism (glutathione Stransferase/spot 43), and ion homeostasis (regucalcin/spot 37; voltage-dependent anion channel/spot 38).

\subsection{Differential expression of the muscle proteome in normal versus $m d x$ diaphragm}

The differential expression of the diaphragm muscle proteome in the normal versus the $\mathrm{x}$-linked dystrophic phenotype is listed in Table 2. Twenty protein spots were found to exhibit changes in the 1- to 6-fold range, of which 19 could be clearly identified as distinct diaphragm muscle proteins. Table 2 lists the fold change in density of individual proteins and gives information on the spot number of these differentially expressed protein species, so that they can be correlated to the numbering in Fig. 4. As can be seen in Table 2 , major skeletal muscle components such as the intermediate filament proteins vimentin (spots 9 and 13) and desmin (spot 11), the extracellular fatty acid transport protein albumin (spot 18 ), creatine kinase (spot 23), the glycolytic enzyme aldolase (spot 25), the electron transferring flavoprotein (spot 32), and malate dehydrogenase of the citric acid cycle (spot 34), as well as an unidentified protein (spot 22), were found to exhibit increased expression levels in mdx diaphragm. In stark contrast, 11 diaphragm proteins were identified that showed a decreased expression in the mdx mouse model of Duchenne muscular dystrophy. These were the metabolic proteins $\beta$-galactosidase (spot 7), the enzyme dihydrolipoamide dehydrogenase of the supramolecular pyruvate dehydrogenase complex (spot 10), the ubiquination factor Fbxo11 protein (spot 14), aldehyde dehydrogenase (spot 15), isocitrate dehydrogenase of the citric acid cycle (spot 21), the glycolytic enzyme glyceraldehydes-3-phosphate dehydrogenase (spot 36 ), the voltage-dependent anion channel (spot 38), adenylate kinase (spot 42), the small heat shock protein $\alpha \mathrm{B}$-crystallin/ cryab protein (spot 47), myosin light chain $2 \mathrm{v}$ (spot 48), and regucalcin (spot 37). The differential expression pattern of creatine kinase and adenylate kinase has been previously documented. The 6-fold reduction of adenylate kinase in $\mathrm{mdx}$ diaphragm agrees with the recently published proteomics analysis of mildly dystrophic mdx hind limb by Ge et al. [28], and shows the reproducibility of comparative approaches that employ mass spectrometry-based proteomics.

With respect to the calcium hypothesis of $\mathrm{x}$-linked muscular dystrophy, the most interesting result was the drastically reduced expression of the cytosolic $\mathrm{Ca}^{2+}$-binding protein regucalcin with a molecular mass of $33.9 \mathrm{kDa}$ and an acidic pI-value of 5.2 (spot 37). This protein spot has previously been identified in two-dimensional liver databases $[34,55]$ and has the SWISS-2DPAGE accession number Q64374 (SM30_MOUSE; gene name RGN/SMP30). The cDNA encoding for regucalcin has the GenBank accession number D86217 [56]. Fig. 5 shows the results of the tryptic peptide fingerprint analysis and lists the 10 peptides ranging from $1057.523 \mathrm{~m} / \mathrm{z}$ to $2152.055 \mathrm{~m} / \mathrm{z}$ that clearly identified this two-dimensional protein spot as regucalcin. This protein, which is also known as senescence marker protein SMP-30 [50], but referred to as regucalcin in the overwhelming majority of published papers [49], had not previously been described in diaphragm muscle fibres. We therefore further characterized this novel diaphragm protein and investigated

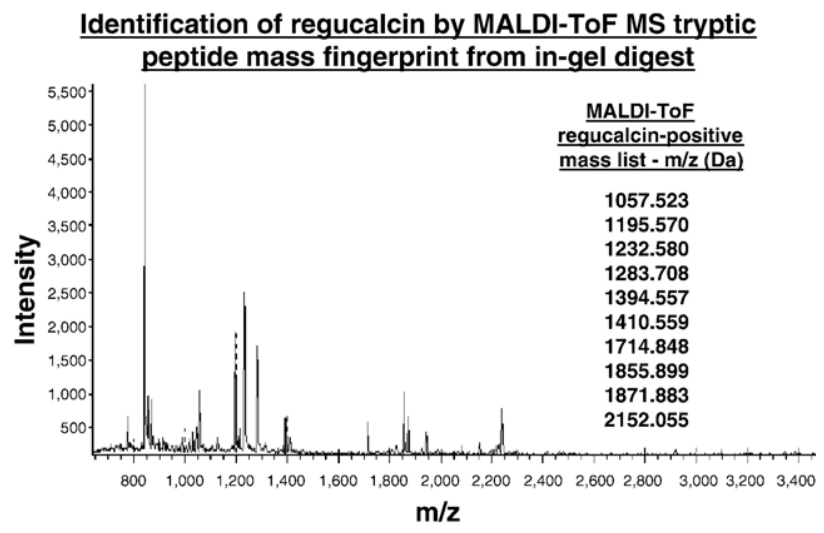

Fig. 5. Mass spectrometric identification of regucalcin in diaphragm muscle. Show is the MALDI-ToF spectrum of regucalcin-positive peptides that identified spot no. 37 in the gel shown in Fig. 4 as a distinct diaphragm muscle protein. Regucalcin has the SWISS-2DPAGE accession number Q64374 (SM30_MOUSE; gene name RGN/SMP30), the GenBank accession number D86217 and the protein identification number gi[6677739]. 

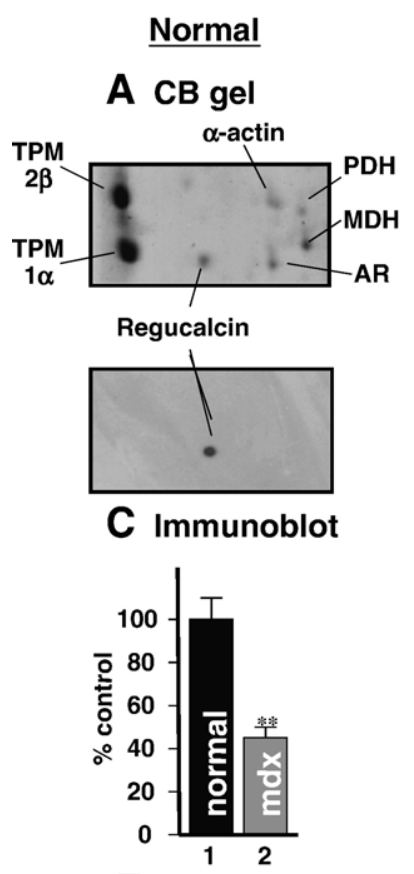

E Immunoblotting mdx

B CB gel
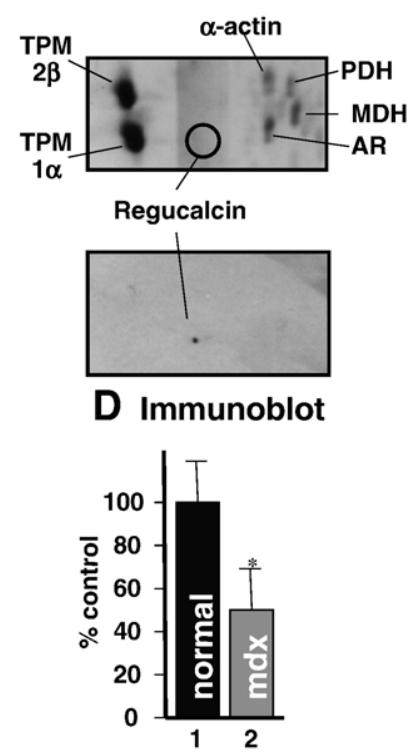

F CB staining

Fig. 6. Two-dimensional immunoblot analysis of the cytosolic $\mathrm{Ca}^{2+}$-binding protein regucalcin in mdx diaphragm. Shown are Hot Coomassie-stained gels $(A, B)$ and $2 \mathrm{D}$ immunoblots $(\mathrm{C}, \mathrm{D})$ that focus on the area of the regucalcin protein spot in normal $(\mathrm{A}, \mathrm{C})$ versus dystrophic $\mathrm{mdx}(\mathrm{B}, \mathrm{D})$ preparations. Protein spots in the vicinity of regucalcin correspond to the two tropomyosin isoforms TPM- $1 \alpha$ and TPM- $2 \beta$, as well as $\alpha$-actin, pyruvate dehydrogenase (PDH), malate dehydrogenase (MDH) and aldehyde reductase (AR). Immunoblots were labelled with antibodies to regucalcin/SMP-30. Panels E and F show the graphical presentation of the immunoblotting and Coomassie-staining of regucalcin $(n=6 ; * P<0.05 ; * * P<0.01$; unpaired students $t$-test). Lanes 1 and 2 represent preparations from normal controls and dystrophic mdx diaphragm, respectively.

its potentially abnormal density in muscular dystrophy by immunoblotting.

\subsection{Reduced expression of regucalcin in dystrophic $m d x$ diaphragm muscle as revealed by two-dimensional immunoblotting}

The comparative immunoblotting analysis of regucalcin expression in normal versus mdx diaphragm, as shown in Fig. 6,

clearly confirmed the results from our mass spectrometry-based proteomics screening. In order to directly compare visually the findings from the protein labelling analysis and the immunodecoration of regucalcin, an enlarged two-dimensional spot pattern is shown in Fig. 6A, B, and the regucalcin immunoblot presented in Fig. 6C, D. The proteins constituting the highly reproducible neighboring $2 \mathrm{D}$ spot pattern surrounding regucalcin in Hot Coomassie-stained gels of normal mouse skeletal muscle were shown to be the two tropomyosin isoforms TPM$2 \beta$ and TPM- $1 \alpha$ on the left side, and $\alpha$-actin, pyruvate dehydrogenase, malate dehydrogenase and aldehyde reductase on the right side (Fig. 6A). Both Hot Coomassie-staining and immuno-decoration demonstrated that the regucalcin protein spot is clearly reduced in mdx preparations (Fig. 6A-D). The graphical presentation of these analyses in Fig. 6E, F shows that regucalcin expression is approximately $50 \%$ reduced in dystrophin-deficient diaphragm muscle. The lower expression levels of regucalcin were shown to exist in both young and old mdx mice. Fig. 7 illustrates the immunoblotting of diaphragm proteins from 3-week-, 9-week-, 11-month- and 20-month-old animals. Immuno-decoration of the $\mathrm{Na}^{+} / \mathrm{K}^{+}$-ATPase (Fig. 7AE) and regucalcin (Fig. $7 \mathrm{~F}-\mathrm{J}$ ) showed that in contrast to the relatively unchanged abundance of the surface ion pump, regucalcin is clearly reduced in mdx diaphragm muscle at all stages of the dystrophic degeneration-regeneration cycle. This is a significant finding with respect to ion homeostasis in muscular dystrophy, since even small disturbances in cytosolic $\mathrm{Ca}^{2+}$-buffering may trigger abnormal regulation of $\mathrm{Ca}^{2+}$ dependent processes that in the long-term might cause muscle fibre necrosis.

\subsection{Reduced expression of regucalcin in mdx diaphragm, heart and limb muscle}

Since Duchenne muscular dystrophy affects, besides the diaphragm, also the heart and limb muscle, a comparative immunoblotting survey was performed with all three types of muscle from 9-week-old mdx mice. Fig. 8 shows the gel electrophoretic separation of normal versus $\mathrm{mdx}$ diaphragm (Fig. 8A, B), limb muscle (Fig. 8C, D) and heart (Fig. 8E, F). Comparative immunoblotting of nitrocellulose replicas of these gels revealed that regucalcin is not only reduced in the dystrophic diaphragm (Fig. 8G, H), but also in dystrophin-
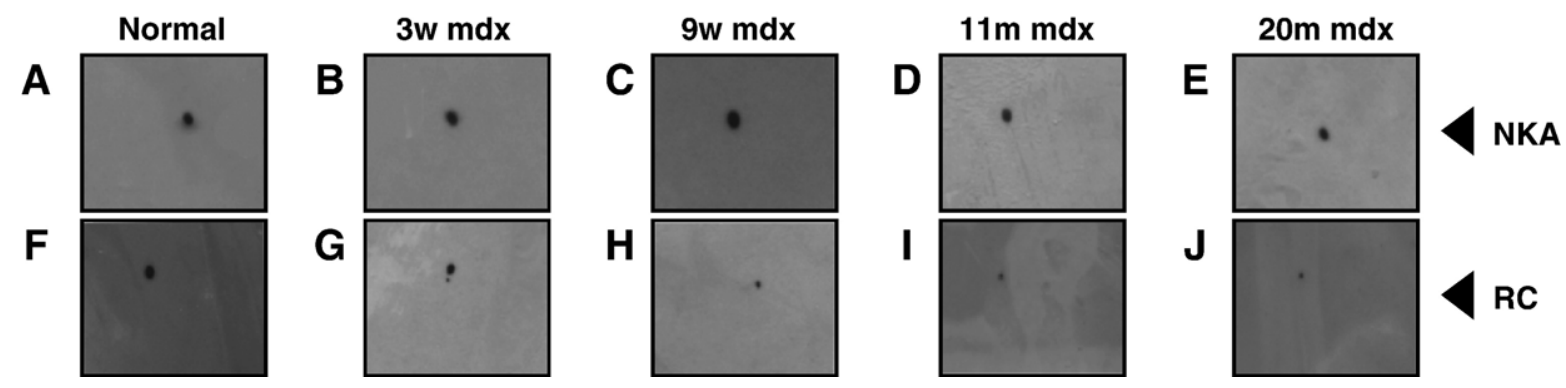

Fig. 7. Two-dimensional immunoblot analysis of regucalcin in young and old mdx diaphragm. Shown are immunoblots that focus on the area of the immuno-decorated protein spot in normal (A, F) versus dystrophic mdx (B-E, G-J) diaphragm preparations. The dystrophic specimens were isolated from 3-week-old (B, G), 9-week-old (C, H), 11-month-old (D, I) and 20-month-old (E, J) animals. The immunoblot analysis was carried out with antibodies to the Na $/ \mathrm{K}^{+}-\mathrm{ATPase}(\mathrm{NKA}$; A-E) and regucalcin $(\mathrm{RC} ; \mathrm{F}-\mathrm{J})$. 


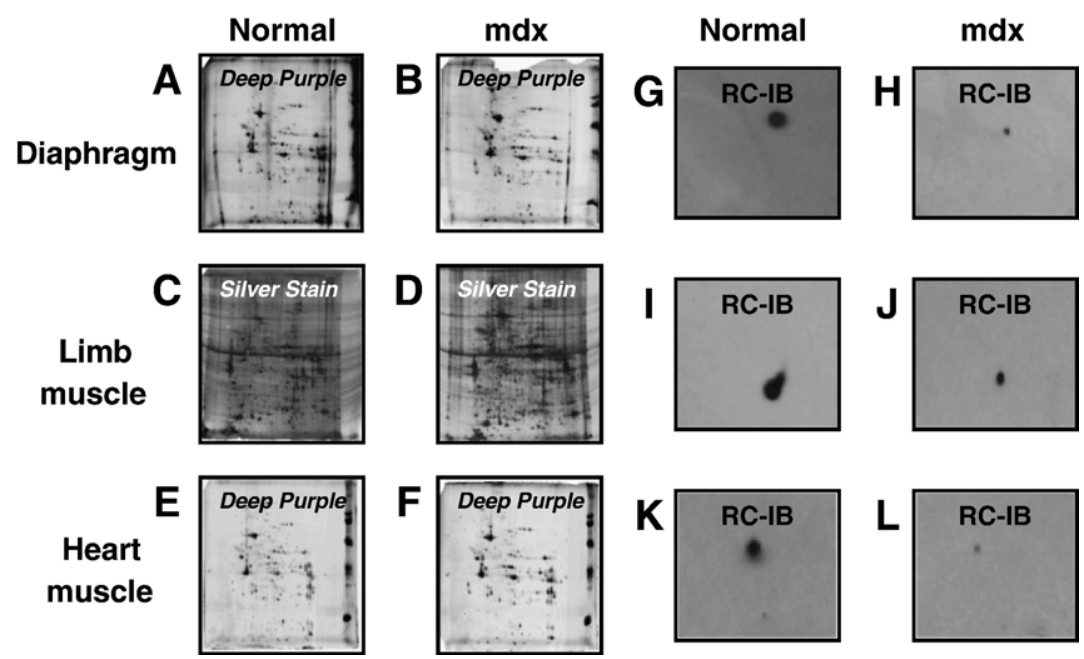

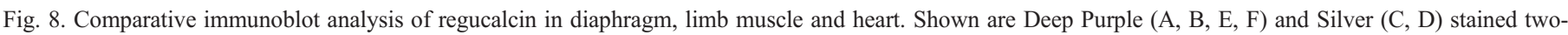

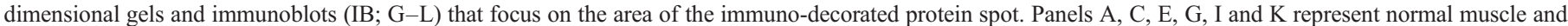

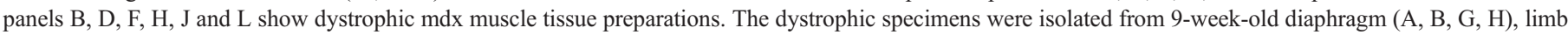
muscle $(\mathrm{C}, \mathrm{D}, \mathrm{I}, \mathrm{J})$ and heart $(\mathrm{E}, \mathrm{F}, \mathrm{K}, \mathrm{L})$. The immunoblot analysis was carried out with an antibody to regucalcin (RC; $\mathrm{G}-\mathrm{L})$.

deficient limb muscle (Fig. 8I, J) and the mdx heart (Fig. 8K, L). Thus, the results from the proteomic profiling of the $\mathrm{mdx}$ diaphragm can be extrapolated to limb muscle and cardiac muscle. This important cytosolic $\mathrm{Ca}^{2+}$-binding protein appears to be reduced in all three muscle tissues.

\section{Discussion}

Despite the fact that animal disease models rarely represent the identical range of clinical symptoms seen in human patients, the dystrophic mdx mouse is widely employed as a suitable system for studying molecular and cellular aspects of muscular dystrophy and to test novel therapeutic approaches [44]. Although the mdx mouse has a milder phenotype, it can be employed as a good model for studying the effect of dystrophin deficiency [45]. The mdx diaphragm is especially affected and exhibits substantial cellular degeneration [42]. Here, we have separated total diaphragm extracts from normal and dystrophic mice by two-dimensional gel electrophoresis in order to study the total muscle complement by mass spectrometry-based proteomics. Certain technical difficulties exist with comparative proteomics approaches that use gel electrophoretic separation techniques. They include an incomplete presentation of certain integral components, very high molecular mass proteins, low abundance proteins and very acidic proteins. However, generally the two-dimensional spot patterns show a large portion of the soluble muscle protein complement so that it is possible to detect major changes in protein expression. This makes the comparative proteomics technique ideal for identifying soluble muscle $\mathrm{Ca}^{2+}$-binding proteins and detect potential changes in neuromuscular diseases.

The overall two-dimensional protein spot pattern of our diaphragm preparations compares well with international databanks and published reports on the electrophoretically separated skeletal muscle proteome [33-35]. Key spots with a unique combination of their isoelectric point and relative molecular mass corresponded to abundant protein species that were clearly identified by mass spectrometry [34]. The comparative 2D software analysis revealed drastic changes in a few protein species, including metabolic enzymes, contractile proteins, heat shock proteins, cytoskeletal elements and ionregulatory proteins. The 6-fold reduction of adenylate kinase in $\mathrm{mdx}$ diaphragm has been previously reported by Ge et al. [28] in mdx hind limb fibres. Loss of adenylate kinase appears to be one of the major changes in dystrophin-deficient fibres. Since the enzymes adenylate kinase and creatine kinase provide a major nucleotide pathway, the lack of adenylate kinase suggests an abnormal regulation of nucleotide ratios in mdx diaphragm and hind limb muscles. The expression of metabolic marker proteins, such as those involved in glycolysis, the citric acid cycle, formation of acetyl-coenzyme A, fatty acid transportation and fatty acid oxidation, was differentially affected. While the enzymes dihydrolipoamide dehydrogenase, aldehyde dehydrogenase, glyceraldehyde-3-phosphate dehydrogenase, galactosidase and isocitrate dehydrogenase were reduced, serum albumin, aldolase and malate dehydrogenase were increased. This indicates major disturbances in muscle metabolism due to the loss of key enzymes and the compensatory up-regulation of other metabolic factors. Possibly, the increased frequency of micro-rupturing of the dystrophic sarcolemma causes the loss of the cellular integrity in certain muscle fibres. This in turn may trigger abnormal fluxes of ions, substrates and co-factors and thereby impair metabolic pathways. Elevated levels of albumin in the mdx diaphragm, shown here by proteomics to be approximately 3-fold, have previously been shown by DupontVersteegden et al. [57]. Skeletal muscle damage appears to be associated with an influx of extracellular fluid components such as albumin.

The intermediate filament components desmin and vimentin were clearly up-regulated in dystrophin-deficient fibres. This could be interpreted as a compensatory mechanism of the dystrophic muscle cell in order to rescue its impaired 
cytoskeletal structure. The increased expression of protein constituents of intermediate filaments may strengthen the loadbearing function of the muscle cytoskeleton. With respect to muscle diseases related to x-linked muscular dystrophy, the 4fold decrease in the small heat shock protein $\alpha \mathrm{B}$-crystallin is very interesting. Muscular atrophy is characterized by a drastic decrease in this desmin-associated protein [58] and patients with mutations in their $\alpha \mathrm{B}$-crystallin gene exhibit progressive skeletal myopathy and respiratory insufficiency [59]. Thus, the loss of this protein in dystrophinopathies may be involved in the down-stream events that render dystrophic muscle fibres more susceptible to cellular degeneration.

Abnormal $\mathrm{Ca}^{2+}$-handling plays a major role in the molecular pathogenesis of dystrophinopathies [11-14]. The result from our proteomics analysis of $\mathrm{mdx}$ diaphragm, that the cytosolic $\mathrm{Ca}^{2+}$-binding protein regucalcin is reduced in dystrophindeficient fibres, supports the calcium hypothesis of muscular dystrophy. In addition to the established increase in sarcolemmal $\mathrm{Ca}^{2+}$-leak channels following membrane re-sealing [11], and the decrease in luminal $\mathrm{Ca}^{2+}$-binding elements sarcalumenin and calsequestrin [16,17], the apparent reduction in regucalcin strongly indicates that abnormal $\mathrm{Ca}^{2+}$-cycling is involved in $\mathrm{mdx}$ fibre degeneration. As reviewed by Yamaguchi $[49,51]$ and Fujita [50], regucalcin is an abundant regulator of $\mathrm{Ca}^{2+}$-homeostasis in the liver. The molecular cloning and sequencing of regucalcin and senescence marker protein SMP30, as well as studies on their tissue distribution, by Shimokawa and Yamaguchi $[60,61]$ and Fujita et al. [62] revealed that both cytosolic components are identical [49,50]. Regucalcin enhances the $\mathrm{Ca}^{2+}$-pumping activity in the plasma membrane, endoplasmic reticulum and mitochondria of various cell types [63-66], making it an important factor in maintaining low cytosolic $\mathrm{Ca}^{2+}$-levels [49]. Regucalcin has previously been shown to be present in liver, kidney, heart and brain [51]. Here, we can show that it is also expressed in diaphragm and limb muscle fibres, and that this cytosolic component is abundant enough to form a distinct Coomassie-stained protein spot in two-dimensional gels of diaphragm homogenates. The reduction of regucalcin in both young and old dystrophin-deficient fibres may trigger a similar degeneration process in the mdx diaphragm as has been observed during $\mathrm{Ca}^{2+}$-induced cell degradation in other cell types. Interestingly, the gene for regucalcin is localized on the X-chromosome [49]. Since Duchenne muscular dystrophy is an x-linked muscle disease, with the dystrophin gene being located on the Xp21 region [1], a fragile $\mathrm{x}$-chromosomal pathology might possibly be involved in this necrotic process. Reduced regucalcin protein levels in the mdx mouse could be related to abnormal gene expression patterns on the affected X-chromosome.

It is surprising that distinct $2 \mathrm{D}$ spots in electrophoretically separated total diaphragm preparations do not represent both sarcalumenin and calsequestrin. Both $\mathrm{Ca}^{2+}$-binding proteins are relatively soluble and are major luminal components of the sarcoplasmic reticulum. Possibly the clustering of calsequestrin in self-aggregated terminal cisternae units [67], and/or the close association of calsequestrin with relatively insoluble membrane proteins of high molecular mass, such as the ryanodine receptor
$\mathrm{Ca}^{2+}$-release channel of $565 \mathrm{kDa}$ [68] or triadin oligomers of above 2,000 $\mathrm{kDa}$ [69], might prevent a sufficient extraction prior to gel electrophoresis [70]. The close interaction between sarcalumenin and the integral $\mathrm{Ca}^{2+}$-ATPase tetramers of the longitudinal tubules [16] might mean that sarcalumenin molecules are difficult to solubilize. It is well known that integral membrane proteins and proteins that exist in vivo as large protein complexes are under-represented in two-dimensional gels from total tissue extracts. Hence, abundant and soluble proteins that are closely linked to insoluble protein species might not be properly extracted from tissue homogenates or may fail to enter the first or second dimension gel system. Both calsequestrin and sarcalumenin appears to fall into this category of muscle proteins. However, despite the fact that we were unable to identify luminal $\mathrm{Ca}^{2+}$-binding proteins via mass spectrometry, the immuno-decoration of both proteins confirmed their drastic reduction in dystrophic fibres, including diaphragm muscle.

In conclusion, the comparative proteomics screening of normal versus mdx diaphragm led to the identification of the cytosolic $\mathrm{Ca}^{2+}$-binding element regucalcin in skeletal muscle. The 2-fold reduction of this $\mathrm{Ca}^{2+}$-regulatory protein in dystrophin-deficient muscle fibres agrees with the concept that abnormal $\mathrm{Ca}^{2+}$-handling is involved in $\mathrm{x}$-linked muscular dystrophy. Since $\mathrm{Ca}^{2+}$-cycling through the cytosol of muscle fibres represents a crucial second messenger system involved in the regulation of various metabolic and physiological processes [71], any disturbances of ion fluxes between the contractile apparatus, metabolic complexes, the transverse tubules, the sarcoplasmic reticulum, the sarcolemma and mitochondria may trigger fibre degeneration. Since the amount of cytosolic $\mathrm{Ca}^{2+}$ ions dictates the overall contractile status of skeletal muscle fibres, $\mathrm{Ca}^{2+}$-cycling through intracellular reservoirs has to be maintained under precise spatial and temporal control. Therefore, the drastic reduction in luminal and cytosolic $\mathrm{Ca}^{2+}$-binding proteins may render dystrophic muscle fibres more susceptible to necrosis. Probably, a causal connection exists between sarcolemmal disintegration, caused primarily by the deficiency in dystrophin, and the $\mathrm{Ca}^{2+}$-dependent proteolysis of key muscle proteins [11]. The destabilization of the dystroglycanmediated linkage between the extracellular matrix and the membrane cytoskeleton seems to cause an influx of extracellular $\mathrm{Ca}^{2+}$-ions via membrane re-sealing. The pathophysiological consequence of increased $\mathrm{Ca}^{2+}$-fluxes into the fibre interior is then exacerbated by the decreased availability of the cytosolic $\mathrm{Ca}^{2+}$-binding element regucalcin and the impaired $\mathrm{Ca}^{2+}$ buffering capacity of the sarcoplasmic reticulum in dystrophic fibres. This molecular scenario of abnormal ion handling in dystrophin-deficient fibres suggests that the therapeutic intervention on the level of $\mathrm{Ca}^{2+}$-homeostasis $[72,73]$ might be a useful option to explore in the development of novel treatment strategies for Duchenne muscular dystrophy.

\section{Acknowledgments}

Research was supported by a principal investigator grant from Science Foundation Ireland (SFI-04/IN3/B614), a project 
grant from Muscular Dystrophy Ireland (MDI-2003) and a training and mobility grant from the European Commission (RTN2-2001-00337), as well as equipment grants from the Irish Health Research Board (HRB-EQ/2003/3, HRB-EQ/2004/2).

\section{References}

[1] A.H. Ahn, L.M. Kunkel, The structural and functional diversity of dystrophin, Nat. Genet. 3 (1993) 283-291.

[2] A. Emery, F. Muntoni, Duchenne muscular dystrophy, 3rd ed., Oxford Univ. Press, Oxford, UK, 2003.

[3] J.M. Ervasti, K. Ohlendieck, S.D. Kahl, M.G. Gaver, K.P. Campbell, Deficiency of a glycoprotein component of the dystrophin complex in dystrophic muscle, Nature 345 (1990) 315-319.

[4] K.G. Culligan, A.J. Mackey, D.M. Finn, P.B. Maguire, K. Ohlendieck, Role of dystrophin isoforms and associated proteins in muscular dystrophy (review), Int. J. Mol. Med. 2 (1998) 639-648.

[5] R.D. Cohn, K.P. Campbell, Molecular basis of muscular dystrophies, Muscle Nerve 23 (2000) 1456-1471.

[6] T.A. Rando, Role of nitric oxide in the pathogenesis of muscular dystrophies: a 'two hit' hypothesis of the cause of muscle necrosis, Microsc. Res. Tech. 55 (2001) 223-235.

[7] J. Ehmsen, E. Poon, K. Davies, The dystrophin-associated protein complex, J. Cell. Sci. 115 (2002) 2801-2803.

[8] K. Ohlendieck, Towards an understanding of the dystrophin-glycoprotein complex: linkage between the extracellular matrix and the subsarcolemmal membrane cytoskeleton, Eur. J. Cell. Biol. 69 (1996) $1-10$.

[9] K.P. Campbell, Three muscular dystrophies: loss of cytoskeletonextracellular matrix linkage, Cell 80 (1995) 675-679.

[10] M.S. Clarke, R. Khakee, P.L. McNeil, Loss of cytoplasmic basic fibroblast growth factor from physiologically wounded myofibers of normal and dystrophic muscle, J. Cell. Sci. 106 (1993) 121-133.

[11] J.M. Alderton, R.A. Steinhardt, Calcium influx through calcium leak channels is responsible for the elevated levels of calcium-dependent proteolysis in dystrophic myotubes, J. Biol. Chem. 275 (2000) 9452-9460.

[12] N. Mallouk, V. Jacquemond, B. Allard, Elevated subsarcolemmal $\mathrm{Ca}^{2+}$ in $\mathrm{mdx}$ mouse skeletal muscle fibres detected with $\mathrm{Ca}^{2+}$-activated $\mathrm{K}^{+}$ channels, Proc. Natl. Acad. Sci. U. S. A. 97 (2000) 4950-4955.

[13] K. Ohlendieck, The pathophysiological role of impaired calcium handling in muscular dystrophy, in: S.J. Winder (Ed.), Molecular Mechanisms of Muscular Dystrophies, Landes Bioscience, Georgetown, TX, 2005, pp. 188-197.

[14] D.G. Allen, N.P. Whitehead, E.W. Yeung, Mechanisms of stretch-induced muscle damage in normal and dystrophic muscle: role of ionic changes, J. Physiol. 567 (2005) 723-735.

[15] K. Culligan, N. Banville, P. Dowling, K. Ohlendieck, Drastic reduction of calsequestrin-like proteins and impaired calcium binding in dystrophic mdx muscle, J. Appl. Physiol. 92 (2002) 435-445.

[16] P. Dowling, P. Doran, K. Ohlendieck, Drastic reduction of sarcalumenin in Dp427-deficient fibres indicates that abnormal calcium handling plays a key role in muscular dystrophy, Biochem. J. 379 (2004) 479-488.

[17] P. Doran, P. Dowling, J. Lohan, K. McDonnell, S. Poetsch, K. Ohlendieck, Subproteomics analysis of $\mathrm{Ca}^{2+}$-binding proteins demonstrates decreased calsequestrin expression in dystrophic mouse skeletal muscle, Eur. J. Biochem. 271 (2004) 3943-3952.

[18] B.D. Johnson, T. Scheuer, W.A. Catterall, Convergent regulation of skeletal muscle $\mathrm{Ca}^{2+}$ channels by dystrophin, the actin cytoskeleton, and cAMP-dependent protein kinase, Proc. Natl. Acad. Sci. U. S. A. 102 (2005) 4191-4196.

[19] A. DeLuca, S. Pierno, A. Liantonio, M. Cetrone, C. Camerino, B. Fraysse, M. Mirabella, A. Servidei, U.T. Ruegg, D. Conte Camerino, Alteration of excitation-contraction coupling mechanism in extensor digitorum longus muscle fibres of dystrophic mdx mouse and potential efficacy of taurine, Br. J. Pharmacol. 132 (2001) 1047-1054.
[20] X. Wang, N. Weisleder, C. Collet, J. Zhou, Y. Chu, Y. Hirata, X. Zhao, Z. Pan, M. Brotto, H. Cheng, J. Ma, Uncontrolled calcium sparks act as a dystrophic signal for mammalian skeletal muscle, Nat. Cell Biol. 7 (2005) 525-530.

[21] P.S. Hedge, I.R. White, C. Debouck, Interplay of transcriptomics and proteomics, Curr. Opin. Biotechnol. 14 (2003) 647-651.

[22] R. Aebersold, M. Mann, Mass spectrometry-based proteomics, Nature 422 (2003) 98-207.

[23] A.V. Tkatchenko, G. Le Cam, J.J. Leger, C.A. Dechesne, Large-scale analysis of differential gene expression in the hindlimb muscles and diaphragm of mdx mouse, Biochim. Biophys. Acta 1500 (2000) 17-30.

[24] Y.W. Chen, P. Zhao, R. Borup, E.P. Hoffman, Expression profiling in the muscular dystrophies: identification of novel aspects of molecular pathophysiology, J. Cell Biol. 151 (2000) 1321-1336.

[25] M. Bakay, P. Zhao, J. Chen, E.P. Hoffman, A web-accessible complete transcriptome of normal human and DMD muscle, Neuromuscul. Disord. 12 (2002) S125-S141.

[26] J.D. Porter, A.P. Merriam, P. Leahy, B. Gong, S. Khanna, Dissection of temporal gene expression signatures of affected and spared muscle groups in dystrophin-deficient $(\mathrm{mdx})$ mice, Hum. Mol. Genet. 12 (2003) $1813-1821$.

[27] J.D. Porter, A.P. Merriam, P. Leahy, B. Gong, J. Feuerman, G. Cheng, S. Khanna, Temporal gene expression profiling of dystrophin-deficient (mdx) mouse diaphragm identifies conserved and muscle group-specific mechanisms in the pathogenesis of muscular dystrophy, Hum. Mol. Genet. 13 (2004) 257-269.

[28] Y. Ge, M.P. Molloy, J.S. Chamberlain, P.C. Andrews, Proteomic analysis of mdx skeletal muscle: great reduction of adenylate kinase 1 expression and enzymatic activity, Proteomics 3 (2003) 1895-1903.

[29] Y. Ge, M.P. Molloy, J.S. Chamberlain, P.C. Andrews, Differential expression of the skeletal muscle proteome in $\mathrm{mdx}$ mice at different ages, Electrophoresis 25 (2004) 2576-2585.

[30] L.P. van den Heuvel, M.H. Farhoud, R.A. Wevers, B.G. van Engelen, J.A. Smeitink, Proteomics and neuromuscular diseases: theoretical concept and first results, Ann. Clin. Biochem. 40 (2003) 9-15.

[31] A.E. Emery, Muscular dystrophy into the new millennium, Neuromuscul. Disord. 12 (2002) 343-349.

[32] C.L. de Hoog, M. Mann, Proteomics, Annu. Rev. Genomics Hum. Genet. 5 (2004) 267-293.

[33] R.J. Isfort, Proteomic analysis of striated muscle, J. Chromatogr. B771 (2002) 155-165.

[34] J.C. Sanchez, D. Chiappe, V. Converset, C. Hoogland, P.A. Binz, S. Paesano, R.D. Appel, S. Wang, M. Sennitt, A. Nolan, M.A. Cawthorne, D.F. Hochstrasser, The mouse SWISS-2D PAGE database: a tool for proteomics study of diabetes and obesity, Proteomics 1 (2001) $136-163$

[35] J.X. Yan, R.A. Harry, R. Wait, S.Y. Welson, P.W. Emery, V.R. Preedy, M.J. Dunn, Separation and identification of rat skeletal muscle proteins using two-dimensional gel electrophoresis and mass spectrometry, Proteomics 1 (2004) 424-434.

[36] J. Kanski, M.A. Alterman, C. Schoneich, Proteomic identification of agedependent protein nitration in rat skeletal muscle, Free Radic. Biol. Med. 35 (2003) 1229-1239.

[37] C. Cieniewski-Bernard, B. Bastide, T. Lefebvre, J. Lemoine, Y. Mounier, J.C. Michalski, Identification of O-linked N-acetylglucosamine proteins in rat skeletal muscle using two-dimensional gel electrophoresis and mass spectrometry, Mol. Cell. Proteomics 3 (2004) $577-585$.

[38] N. Okumura, A. Hashida-Okumura, K. Kita, M. Matsubae, T. Matsubara, T. Takao, K. Nagai, Proteomic analysis of slow- and fast-twitch skeletal muscles, Proteomics 5 (2005) 2896-2906.

[39] P. Donoghue, P. Doran, P. Dowling, K. Ohlendieck, Differential expression of the fast skeletal muscle proteome following chronic low-frequency stimulation, Biochim. Biophys. Acta 1752 (2005) 166-176.

[40] M.K. Doherty, L. McLean, J.R. Hayter, J.M. Pratt, D.H. Robertson, A. El-Shafei, S.J. Gaskell, R.J. Beynon, The proteome of chicken skeletal muscle: changes in soluble protein expression during growth in a layer strain, Proteomics 4 (2004) 2082-2093. 
[41] J. Bouley, B. Meunier, C. Chambon, S. De Smet, J.F. Hocquette, B. Picard, Proteomic analysis of bovine skeletal muscle hypertrophy, Proteomics 5 (2005) 490-500.

[42] H.H. Stedman, H.L. Sweeney, J.B. Shrager, H.C. Maguire, R.A. Panettieri, B. Petrof, M. Narusawa, J.M. Leferovich, J.T. Sladky, A.M. Kelly, The mdx mouse diaphragm reproduces the degenerative changes of Duchenne muscular dystrophy, Nature 352 (1991) 536-539.

[43] P. Sicinski, Y. Geng, A.S. Ryder-Cook, E.A. Barnard, M.G. Darlison, P.J. Barnard, The molecular basis of muscular dystrophy in the mdx mouse: a point mutation, Science 244 (1989) 1578-1580.

[44] M. Durbeej, K.P. Campbell, Muscular dystrophies involving the dystrophin-glycoprotein complex: an overview of current mouse models, Curr. Opin. Genet. Dev. 12 (2002) 349-361.

[45] J.F. Watchko, T.L. O’Day, E.P. Hoffman, Functional characteristics of dystrophic skeletal muscle: insights from animal models, J. Appl. Physiol. 93 (2002) 407-417.

[46] M. Yamaguchi, A novel $\mathrm{Ca}^{2+}$-binding protein regucalcin and calcium inhibition: regulatory role in liver cell function, in: K. Kohama (Ed.), Calcium Inhibition, CRC Press, Boca Raton, FL, 1992, pp. 19-41.

[47] M. Yamaguchi, T. Yamamoto, Purification of calcium binding substance from soluble fraction of normal rat liver, Chem. Pharm. Bull. (Tokyo) 26 (1978) 1915-1918.

[48] M. Yamaguchi, S. Mori, Effect of $\mathrm{Ca}^{2+}$ and $\mathrm{Zn}^{2+}$ on $5^{\prime}$-nucleotidase activity in rat liver plasma membranes: hepatic calcium-binding protein (regucalcin) reverses the $\mathrm{Ca}^{2+}$ effect, Chem. Pharm. Bull. (Tokyo) 36 (1988) 321-325.

[49] M. Yamaguchi, Role of regucalcin in maintaining cell homeostasis and function (review), Int. J. Mol. Med. 15 (2005) 371-389.

[50] T. Fujita, Senescence marker protein-30 (SMP30): structure and biological function, Biochem. Biophys. Res. Commun. 254 (1999) 1-4.

[51] M. Yamaguchi, Role of regucalcin in calcium signaling, Life Sci. 66 (2000) 1769-1780.

[52] M.J. Dunn, S.J. Bradd, Separation and analysis of membrane proteins by SDS-polyacrylamide gel electrophoresis, Methods Mol. Biol. 19 (1993) 203-210.

[53] H. Towbin, T. Staehelin, J. Gordon, Electrophoretic transfer of proteins from polyacrylamide gels to nitrocellulose sheets: procedure and some applications, Proc. Natl. Acad. Sci. U. S. A. 76 (1979) $4350-4354$

[54] S.J. Bradd, M.J. Dunn, Analysis of membrane proteins by western blotting and enhanced chemiluminescence, Methods Mol. Biol. 19 (1993) 211-218.

[55] N.L. Anderson, R. Esquer-Blasco, J.P. Hoffmann, L. Meheus, J. Raymackers, S. Steiner, F. Witzmann, N.G. Anderson, An updated twodimensional gel database of rat liver proteins useful in gene regulation and drug effect studies, Electrophoresis 16 (1995) 1977-1981.

[56] T. Murata, M. Yamaguchi, Molecular cloning of the cDNA coding for regucalcin and its mRNA expression in mouse liver: the expression is stimulated by calcium administration, Mol. Cell. Biochem. 173 (1997) $127-133$.
[57] E.E. Dupont-Versteegen, A.M. Kitten, M.S. Katz, R.J. McCarter, Elevated levels of albumin in soleus and diaphragm muscles of mdx mice, Proc. Soc. Exp. Biol. Med. 213 (1996) 281-286.

[58] Y. Atomi, S. Yamada, T. Nishida, Early changes of alpha B-crystallin mRNA in rat skeletal muscle to mechanical tension and denervation, Biochem. Biophys. Res. Commun. 181 (1991) 1323-1330.

[59] D. Paulin, A. Huet, L. Khanamyrian, Z. Xue, Desminopathies in muscle disease, J. Pathol. 204 (2004) 418-427.

[60] N. Shimokawa, M. Yamaguchi, Calcium administration stimulates the expression of calcium-binding protein regucalcin mRNA in rat liver, FEBS Lett. 305 (1992) 151-154.

[61] N. Shimokawa, M. Yamaguchi, Molecular cloning and sequencing of the cDNA coding for a calcium-binding protein regucalcin from rat liver, FEBS Lett. 327 (1993) 251-255.

[62] T. Fujita, T. Shirasawa, K. Uchida, N. Maruyama, Isolation of cDNA clone encoding rat senescence marker protein-30 (SMP30) and its tissue distribution, Biochim. Biophys. Acta 1132 (1992) 297-305.

[63] M. Yamaguchi, R. Nakajima, Role of regucalcin as an activator of sarcoplasmic reticulum $\mathrm{Ca}^{2+}$-ATPase activity in rat heart muscle, J. Cell. Biochem. 86 (2002) 184-193.

[64] Y. Hanahisa, M. Yamaguchi, Decrease in $\mathrm{Ca}^{2+}$-ATPase activity in the brain plasma membrane of rats with increasing age: involvement of brain calcium accumulation, Int. J. Mol. Med. 7 (2001) 407-411.

[65] T. Hamano, M. Yamaguchi, Inhibitory role of regucalcin in the regulation of $\mathrm{Ca}^{2+}$ dependent protein kinases activity in rat brain neurons, J. Neurol. Sci. 183 (2001) 33-38.

[66] H. Takahashi, M. Yamaguchi, Stimulatory effect of regucalcin on ATPdependent $\mathrm{Ca}^{2+}$ uptake activity in rat liver mitochondria, J. Cell. Biochem. 78 (2000) 121-130.

[67] P.B. Maguire, F.N. Briggs, N. Lennon, K. Ohlendieck, Oligomerisation is an intrinsic property of calsequestrin in normal and stimulated canine skeletal muscle, Biochem. Biophys. Res. Commun. 240 (1997) 721-727.

[68] B. Murray, K. Ohlendieck, Complex formation between calsequestrin and the ryanodine receptor in fast- and slow-twitch rabbit skeletal muscle, FEBS Lett. 429 (1998) 317-322.

[69] G.R. Froemming, B.E. Murray, K. Ohlendieck, Self-aggregation of triadin in the sarcoplasmic reticulum of rabbit skeletal muscle, Biochim. Biophys. Acta 1418 (1999) 197-205.

[70] L. Glover, S. Quinn, M. Ryan, Pette, K. Ohlendieck, Supramolecular calsequestrin complex: protein-protein interactions in chronic lowfrequency stimulated muscle, postnatal development and ageing, Eur. J. Biochem. 269 (2002) 4607-4616.

[71] M.W. Berchtold, H. Brinkmeier, M. Muntener, Calcium ion in skeletal muscle: its crucial role for muscle function, plasticity, and disease, Physiol. Rev. 80 (2000) 1215-1265.

[72] T.S. Khurana, K.E. Davies, Pharmacological strategies for muscular dystrophy, Nat. Rev., Drug Discov. 2 (2003) 379-390.

[73] J.G. Tidball, M. Wehling-Henricks, Evolving therapeutic strategies for Duchenne muscular dystrophy: targeting downstream events, Pediatr. Res. 56 (2004) 831-841. 